\title{
Pulmonary Hypertension and Erythropoietin
}

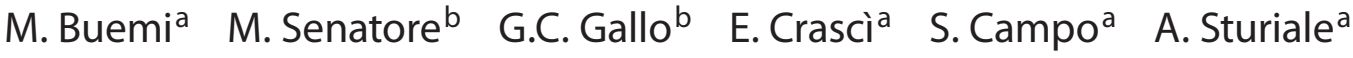 \\ G. Coppolino ${ }^{a}$ D. Bolignano ${ }^{a} \quad$ N. Frisina ${ }^{a}$ \\ ${ }^{a}$ Chair of Nephrology, Department of Internal Medicine, University of Messina, Messina, and \\ ${ }^{b}$ Hemodialysis Unit S. Marco Argentano, Castrovillari, Italy
}

\section{Key Words}

Chronic hemodialysis $\cdot$ Chronic renal failure $\cdot$

Erythropoietin $\cdot$ Hypertension $\cdot$ Nitric oxide $\cdot$ Vascular

access, hemodialysis

\begin{abstract}
Numerous uremic patients on hemodialysis have pulmonary hypertension attributable to the presence of arteriovenous fistulas, vascular calcification, and endothelial dysfunction due to alterations in the balance between vasoconstrictive and vasodilatory substances. For these reasons, the effects of recombinant human erythropoietin, a drug widely used in patients on dialysis, on the pulmonary circulation were studied. Some authors maintain that recombinant human erythropoietin has an antihypertensive effect, while others have observed that this hormone induces a reduction in pulmonary arterial pressure due to its vasoactive and stimulatory effects on endothelial and smooth muscle cell precursors.

Copyright $\odot 2007$ S. Karger AG, Basel
\end{abstract}

\section{Pulmonary Hypertension (PH): The Problem}

It is widely known that uremic patients with end-stage renal disease on chronic hemodialysis having an arteriovenous fistula are at an increased risk of atherosclerosis and cardiovascular diseases, including $\mathrm{PH}$. PH occurs in $40 \%$ of the patients, its instrumental signs being unequiv-

\section{KARGER}

Fax +4161306 1234 E-Mail karger@karger.ch www.karger.com
(C) 2007 S. Karger AG, Base

$1420-4096 / 07 / 0304-0248 \$ 23.50 / 0$

Accessible online at: www.karger.com/kbr ocable and exposing the patients to an increased morbidity and mortality $[1,2]$. Uremia affects the lung with pathological alterations that worsen, as the disease progresses. Particularly noteworthy are anomalies in the transport of respiratory gases, alterations in diffusive mechanisms, diminution in ventilatory processes at rest, and functional alterations in the respiratory muscles $[3,4]$. These patients, moreover, almost always present a significantly higher cardiac ejection fraction, low hemoglobin and hematocrit levels, and an increase in the pulmonary arterial pressure (PAP). The PAP usually tends to normalize, whenever arteriovenous fistula closure is undertaken, e.g., when the patient undergoes renal transplantation [5]. Chronic hypoxia elicits a number of physiological responses that result in $\mathrm{PH}$. Hypoxia causes active pulmonary vasoconstriction as well as a structural remodeling of the pulmonary arterial vasculature. Both of these responses diminish the luminal diameter of the small pulmonary arteries, increasing vascular resistance and contributing to the development of $\mathrm{PH}$ [6]. In table 1, we have summarized the most common pathological lung alterations in uremic patients.

\section{PH in Hemodialysis Patients: The Reason}

From a pathophysiological point of view, an increase in the cardiac output under normal conditions cannot in itself cause $\mathrm{PH}$, considering the enormous capacity of the small circulation. However, it is also true that in patients

Prof. Michele Buemi

Via Salita Villa Contino 30

IT-98100 Messina (Italy)

Tel. +39 090221 2396, Fax +39090 293 5162, E-Mail buemim@unime.it 
Table 1. The most common pathological lung alterations in hemodialysis patients

(1) Anomalies in the transport of respiratory gases

(2) Diminution in the ventilatory processes at rest

(3) Functional alteration in the respiratory muscles

(4) Increased uremia-mediated vascular pulmonary resistance

(5) Vascular calcifications with thickening of pulmonary vessels, alveolar interstitium, and wall of the respiratory tree

(6) Increase of the vascular tone of the small pulmonary circulation, mediated by an attenuated production of nitric oxide

with end-stage renal disease this circulation may not be able to bear the increase in the cardiac load induced by an arteriovenous fistula. Not only does the increase in the ejection fraction contribute to this, but so does a reduced vasodilatory response cause the histological modifications associated with uremia which are vascular calcifications with thickening of the pulmonary vessels and endothelial dysfunction [7]. It is, therefore, possible that the pulmonary circulation of patients on chronic dialysis is the site of excessive vasoconstriction. Hormonal-metabolic alterations associated with uremia could be the cause of the increased vascular pulmonary resistance [8]. $\mathrm{PH}$ involves vasoconstriction and obliteration of the lumen of small vessels in the lungs by plexiform lesions, resulting in an increased resistance to flow. The proposed mechanisms for the formation of plexiform lesions include dysregulation of endothelial growth and angiogenic responses to local triggers [9]. Moreover, the phenomenon of extraosseous calcifications is very common in patients on chronic hemodialysis and involves different anatomical regions, including heart, kidney, and stomach $[10,11]$. At the pulmonary level, calcium is deposited in the alveolar interstitium and in the wall of the respiratory tree, the main paths to the bronchioles, as well as in the depth of the pulmonary vessels. In their study, Yigla et al. [12], utilizing bone scintigraphy with ${ }^{99 \mathrm{~m}} \mathrm{Tc}$-methylene diphosphonate, showed calcifications at the pulmonary level in about $40 \%$ of their hemodialysis patients, without finding a direct correlation between pulmonary uptake and PAP values. Although the consequences of calcifications of aorta and coronary vessels are known, it is equally evident that this phenomenon also concerns the small peripheral vessels. However, no in-depth studies have been conducted to clarify this aspect.

Also, in the absence of phenomena of vascular calcification, it is known that uremic patients have anomalies in the endothelial function, a mechanism through which they are exposed to a higher risk for the development of early atherosclerosis. It is known that vascular tone and its function are physiologically regulated at the local level by a balance between vasodilation, induced principally by prostacyclin and nitric oxide, and vasoconstriction, mediated above all by thromboxane $\mathrm{A}_{2}$ and endothelin-1 [13]. Nitric oxide also inhibits platelet activation, adhesion, and aggregation and modulates the interaction between leukocytes and endothelial cells [14]. Endothelin-1, apart from its vasoconstrictive action, also has an important mitogenic activity, and its hematological levels are increased during the course of $\mathrm{PH}$ [15]. However, in their recent study, Nakhoul et al. [16] demonstrated that the endothelin-1 concentration, although statistically significantly elevated in patients on hemodialysis as compared with healthy subjects, is not correlated with $\mathrm{PH}$; in the same study [16], the authors found, on the other hand, that the concentrations of nitric oxide metabolites $\left(\mathrm{NO}^{2+}\right.$, $\mathrm{NO}^{3}$ ) had a different behavioral pattern. Although the values of patients on hemodialysis were similar to those of normal individuals, the subgroup of patients with $\mathrm{PH}$ in a predialytic stage had levels of circulating nitric oxide that were lower than those in patients without PH. During the dialysis session, moreover, the levels of these metabolites increased significantly, and this increase was more marked in patients without PH. Given the vasodilatory and antimitogenic properties of nitric oxide, this study suggests that the attenuated production of this substance, basal and induced by the hemodialysis session, in patients with $\mathrm{PH}$ can be responsible for an increase in vascular tone in the small circulation. Moreover, the temporary normalization of PAP and cardiac output in hemodialyzed patients who undergo arteriovenous fistula closure or renal transplantation appears to indicate that the excessive pulmonary flow could be involved in the pathogenesis of this disease.

\section{PH: The Erythropoietin (EPO) Role}

It is, therefore, reasonable to ask ourselves whether traditional drugs prescribed for patients on dialysis, including anticoagulants, diuretics, digoxin, calcium antagonists, vasodilators, and antiproliferative agents, can reduce $\mathrm{PH}$. On the contrary, other drugs, commonly taken by these patients, could play an important role in the genesis of $\mathrm{PH}$. In this context, of particular interest is recombinant human EPO, a drug with an endotheliummediated activity and which is utilized by all patients on dialysis. 
The data reported in the literature appear, however, to suggest that chronic EPO treatment has an antihypertensive action, at least under experimental conditions. In a recent study, Satoh et al. [17] reported that the endogenous EPO/EPO receptor system prevents the development of $\mathrm{PH}$ during chronic hypoxia in mice in vivo through the recruitment of epithelial progenitor cells, suggesting the therapeutic importance of this system for the treatment of $\mathrm{PH}$.

These data are particularly significant in animals made genetically deficient of the EPO receptor at the level of the cardiovascular system. Also the mobilization of the endothelial progenitor cells and their recruitment by the pulmonary endothelium appear to be compromised. Hypoxia, moreover, would increase the expression of the EPO receptor on pulmonary endothelial cells of control rats, whereas in knockout rats it would activate the endothelial enzyme nitric oxide synthase. Finally, the EPO/ EPO receptor system would play a protective role in the pulmonary endothelium, inhibiting the development of $\mathrm{PH}$ induced by hypoxia.

Weissmann et al. [18] have studied the pulmonary vascular tree in transgenic rats that had overexpression of EPO under conditions of both normoxia and chronic hypoxia. Notwithstanding the increase in hematocrit, the rats maintained in normoxia did not develop right ventricular hypertrophy. The numbers of vessels with a diameter of 51-95 $\mu \mathrm{m}$ and $>155 \mu \mathrm{m}$ were found to be increased, while the percentage of small vessels $(30-50 \mu \mathrm{m})$ was diminished. Also vascular pulmonary resistance, hypoxic vasoconstriction, measured in isolated perfused lungs, and vasoconstriction induced by a thromboxane $\mathrm{A}_{2}$ mimetic (U-46619) tended to be reduced. Moreover, after chronic hypoxia, the vascular resistance and the vasoconstrictive responses to hypoxia were also significantly reduced in transgenic rats as compared with controls and the grade of muscularization of the pulmonary vessels as well. According to these experimental data in animals, the congenital overexpression of EPO would appear to have an antihypertensive pulmonary effect, both at structural and functional levels.

An important question is the role played by polycy themia and EPO administration. In animal models, Walker et al. [19] did not observe any significant effect of recombinant EPO induced polycythemia on the PAP. These authors hypothesized that it is the local shear stress that induces release of nitric oxide, offering a protective effect against the development of $\mathrm{PH}$.

This mechanism could be ineffective in hemodialysis patients. In fact, hemodialysis patients show low hemato- crit levels despite EPO treatment, exerting shear stress, stimulating nitric oxide release.

Other authors [20] have administered EPO to mice with a different sensitivity to chronic hypoxia and have demonstrated that the drug does not increase the right ventricle/body weight ratio (index of ventricular hypertrophy) as well as the systolic pressure peak in hypoxia. In another study [21], transgenic mice with constitutional overexpression of the EPO gene, in a way, however, independent of oxygen, presented polycythemia notwithstanding the fact that they had a normal arterial pressure. However, the PAP was found to be increased in vivo, and it decreased, on the other hand, in isolated perfused lungs. The pulmonary vascular apparatus was characterized by a high production of prostacyclin, a strong expression of endothelial nitric oxide synthase, and a reduced thickness of the smooth muscle sheath of the pulmonary vessels. The fact that these transgenic and polycythemic animals developed a marked $\mathrm{PH}$ in vivo but not in vitro suggests the pathogenic role of the blood hyperviscosity in this experimental model. Polycythemia, therefore, would, in this sense, play a role independent of the development of $\mathrm{PH}$. The lungs of these transgenic mice, moreover, have shown a mechanism of adaptation to the high PAP: an increase in the local synthesis of substances with a vasodilatory action and a reduction in the vascular smooth muscle tone. On studying the blood flow of the human pretibial muscle by means of ${ }^{133}$ Xe clearance, Buemi et al. [22] found an EPO-induced reduction in postischemic vasodilation. Moreover, in anesthetized rats subjected to hemorrhagic shock by intermittent bleeding, EPO administration significantly increased the mean arterial pressure, the survival time, and the percentage of animals surviving with respect to untreated controls [23]. EPO also seems to be able to inhibit acetylcholine-induced cutaneous vasodilation and can stimulate the endothelial release of endothelin and inhibit nitric oxide, a potent vasodilator [24]. A possible explanation for the diverging results following EPO treatment can be different administration modalities. Experimental models used chronic EPO treatment, while in human models infusion of single acute doses leads to enhanced PAP.

Regarding the pulmonary resistance, in a previous study, Allegra et al. [25], using a catheter placed in the pulmonary artery, performed a hemodynamic evaluation in 2 patients with hypovolemic shock. EPO administration caused an increase in the pulmonary vascular resistance and in the mean PAP. Moreover, Allegra et al. [26], in 10 patients with chronic cor pulmonale and marked signs of right ventricular hypertrophy and a pul- 
Table 2. Controversial influence of EPO in establishing a $\mathrm{PH}$ status

\begin{tabular}{ll}
\hline Antipulmonary hypertension & Pulmonary hypertensive effect \\
\hline $\begin{array}{ll}\text { Animal Models } \\
\text { Remodeling operated by endothelial progenitor cells [17] }\end{array}$ & $\begin{array}{l}\text { In vivo effect on the PAP of polycythemia [21] } \\
\text { Acute EPO administration in shocked rats [23] } \\
\text { Structural adaptation to hematological viscosity enhancement [18, 20] }\end{array}$ \\
$\begin{array}{ll}\text { Interstitial and perivascular fibrosis [29] } \\
\text { Upregulation of EPO receptor in the lung vessels [30] }\end{array}$ \\
\hline Clinical Models & $\begin{array}{l}\text { Acute EPO administration in shocked humans [25] } \\
\text { Acute EPO administration in chronic cor pulmonale [26] }\end{array}$ \\
\hline
\end{tabular}

monary pressure $>35 \mathrm{~mm} \mathrm{Hg}$, have demonstrated that an intravenous bolus infusion of recombinant human EPO beta $(70 \mathrm{U} / \mathrm{kg})$ had an effect on the vascular pulmonary resistance. Such observations were recently made in vivo in animal models also by Satoh et al. [17]. The action of EPO on the pathophysiology of chronic cor pulmonale may, however, not be limited to its vasomotor effect on the pulmonary circulation; it may also impact on pulmonary vascular remodeling. It is well known that EPO can influence the proliferation process of cell types other than erythroid precursors, such as endothelial progenitor cells and smooth muscle cells $[27,28]$. In EPO-transgenic mice, the relative lung weight is increased, the interalveolar septa have a greater thickness, and this is accompanied by interstitial and perivascular fibrosis [29]. Foster et al. [30] have demonstrated that developmental lung growth involves paracrine EPO signaling with parallel upregulation of the EPO receptor.

It may, therefore, be suggested that the chronic increase in endogenous EPO concentrations, present in patients with chronic obstructive bronchopathy, contributes to the thickening of the arterial wall of the pulmonary vessels, typical of chronic pulmonary heart disease.

The data obtained appear to confirm the importance of the role played by EPO in the pulmonary circulation, but also appear to partly contradict other reported data cited above. A significant increase in the indices of vas- cular pulmonary resistance has, in fact, been observed immediately after EPO administration. In table 2, we have summarized animal (preclinical) and human models showing experimentally the controversial influence of $\mathrm{EPO}$ in establishing a $\mathrm{PH}$ status.

\section{EPO and PH: An Open Question}

Uremic patients represent a particular model of $\mathrm{PH}$ correlated with hormone-metabolic alterations characteristic of renal disease itself. As compared with the healthy population, in fact, important phenomena of vascular calcification and lacerations are observed in the balance of vasoconstrictive substances, like thromboxane $\mathrm{A}_{2}$ and endothelin-1, and vasodilator substances, like prostacyclins and nitric oxide. The use of substances with a vasoactive action, like EPO, therefore, continues to be a controversial issue. Together with the protective role of the hormone, evidenced in different studies using animal models, an increase in the pulmonary vascular resistance has been found in humans which is probably correlated not only with the vasomotor effect but also with the vascular remodeling due to stimulation of the EPO receptor. In the light of these data, further in-depth studies to be performed in humans are required; they should be conducive to regulating the use of this hormone in patients at an increased risk of developing $\mathrm{PH}$, such as uremic patients.
References

Pulmonary Hypertension and

Erythropoietin
Abassi Z, Nakhoul F, Khankin E, Reisner SA, Yigla M: Pulmonary hypertension in chronic dialysis patients with arteriovenous fistula: pathogenesis and therapeutic prospective. Curr Opin Nephrol Hypertens 2006; 15 : 353-360.

-2 Yigla M, Abassi Z, Reisner SA, Nakhoul F: Pulmonary hypertension in hemodialysis patients: an unrecognized threat. Semin Dial 2006; 19:353-357.

-3 Lang SM, Becker A, Fischer R, Huber RM, Schiffl H: Acute effects of hemodialysis on lung function in patients with end-stage renal disease. Wien Klin Wochenschr 2006; 118:108-113.

Erythropoietin

Kidney Blood Press Res 2007;30:248-252 
-4 Karacan O, Tutal E, Uyar M, Eyuboglu FO, Sezer S, Ozdemir FN: Pulmonary function in uremic patients on long-term hemodialysis. Ren Fail 2004;26:273-278.

$\checkmark 5$ Karacan O, Tutal E, Colak T, Sezer S, Eyuboglu FO, Haberal M: Pulmonary function in renal transplant recipients and end-stage renal disease patients undergoing maintenance dialysis. Transplant Proc 2006;38: 396-400.

6 Rabinovitch M, Gamble W, Nadas AS, Miettinen OS, Reid L: Rat pulmonary circulation after chronic hypoxia: hemodynamic and structural features. Am J Physiol 1979;236: H818-H827.

7 Young PR Jr, Rohr MS, Marterre WF Jr: High-output cardiac failure secondary to a brachiocephalic arteriovenous hemodialysis fistula: two cases. Am Surg 1998;64:239241.

$>8$ Thambyrajah J, Landray MJ, McGlynn FJ, Jones HJ, Wheeler DC, Townend JN: Abnormalities of endothelial function in patients with predialysis renal failure. Heart 2000;83: 205-209.

-9 Jeffery TK, Morrell NW: Molecular and cellular basis of pulmonary vascular remodeling in pulmonary hypertension. Prog Cardiovasc Dis 2002;45:173-202.

10 Davies MR, Hruska KA: Pathophysiological mechanisms of vascular calcification in endstage renal disease. Kidney Int 2001;60:472479.

-11 Haydar AA, Hujairi NM, Covic AA, Pereira D, Rubens M, Goldsmith DJ: Coronary artery calcification is related to coronary atherosclerosis in chronic renal disease patients: a study comparing EBCT-generated coronary artery calcium scores and coronary angiography. Nephrol Dial Transplant 2004;19: 2307-2312.

-12 Yigla M, Keidar Z, Safadi I, Tov N, Reisner SA, Nakhoul F: Pulmonary calcification in hemodialysis patients: correlation with pulmonary artery pressure values. Kidney Int 2004;66:806-810.

13 Rabelink T, Koomans H: Endothelial function and the kidney. An emerging target for cardiovascular therapy. Drugs 1997;53 (Suppl 1):11-19.
14 Wever R, Boer P, Hijmering M, Stroes E, Verhaar M, Kastelein J, Versluis K, Lagerwerf F, van Rijn H, Koomans H, Rabelink T: Nitric oxide production is reduced in patients with chronic renal failure. Arterioscler Thromb Vasc Biol 1999;19:1168-1172.

15 Brooks DP: Role of endothelin in renal function and dysfunction. Clin Exp Pharmacol Physiol 1996;23:345-348.

-16 Nakhoul F, Yigla M, Gilman R, Reisner SA, Abassi Z: The pathogenesis of pulmonary hypertension in haemodialysis patients via arterio-venous access. Nephrol Dial Transplant 2005;20:1686-1692.

-17 Satoh K, Kagaya Y, Nakano M, Ito Y, Ohta J, Tada H, Karibe A, Minegishi N, Suzuki N, Yamamoto M, Ono M, Watanabe J, Shirato K, Ishii N, Sugamura K, Shimokawa H: Important role of endogenous erythropoietin system in recruitment of endothelial progenitor cells in hypoxia-induced pulmonary hypertension in mice. Circulation 2006;113: 1442-1450.

18 Weissmann N, Manz D, Buchspies D, Keller S, Mehling T, Voswinckel R, Quanz K, Ghofrani HA, Schermuly RT, Fink L, Seeger W, Gassmann M, Grimminger F: Congenital erythropoietin over-expression causes 'antipulmonary hypertensive' structural and functional changes in mice, both in normoxia and hypoxia. Thromb Haemost 2005;94: $630-638$.

19 Walker BR, Resta TC, Nelin LD: Nitric oxide-dependent pulmonary vasodilation in polycythemic rats. Am J Physiol Heart Circ Physiol 2000;279:H2382-H2389.

20 Petit RD, Warburton RR, Ou LC, BrinckJohnson T, Hill NS: Exogenous erythropoietin fails to augment hypoxic pulmonary hypertension in rats. Respir Physiol 1993;91: 271-282.

21 Hasegawa J, Wagner KF, Karp D, Li D, Shibata J, Heringlake M, Bahlmann L, Depping R, Fandrey J, Schmucker P, Uhlig S: Altered pulmonary vascular reactivity in mice with excessive erythrocytosis. Am J Respir Crit Care Med 2004;169:829-835.
22 Buemi M, Allegra A, Lagana A, Aloisi C, Morabito N, Baldari S, Privitera M, Palella S, Imbesi D, Villari C, et al: Is erythropoietininduced hypertension a phenomenon due to the intracellular $\mathrm{Ca}^{++}$mobilisation? Int Angiol 1994;13:75-77.

23 Buemi M, Allegra A, Squadrito F, Buemi AL, Lagana A, Aloisi C, Frisina N: Effects of intravenous administration of recombinant human erythropoietin in rats subject to hemorrhagic shock. Nephron 1993;65:440443.

24 Calapai G, Marciano MC, Corica F, Allegra A, Parisi A, Frisina N, Caputi AP, Buemi M: Erythropoietin protects against brain ischemic injury by inhibition of nitric oxide formation. Eur J Pharmacol 2000;401:349-356.

25 Allegra A, Galasso A, Siracusano L, Aloisi C, Corica F, Lagana A, Frisina N, Buemi M: Administration of recombinant erythropoietin determines increase of peripheral resistances in patients with hypovolemic shock. Nephron 1996;74:431-432.

26 Allegra A, Giacobbe MS, Corvaia E, Cinquegrani M, Corvaja E, Giorgianni G, Buemi M: Possible role of erythropoietin in the pathogenesis of chronic cor pulmonale. Nephrol Dial Transplant 2005;20:2866-2867.

27 Bahlmann FH, De Groot K, Spandau JM, Landry AL, Hertel B, Duckert T, Boehm SM, Menne J, Haller H, Fliser D: Erythropoietin regulates endothelial progenitor cells. Blood 2004;103:921-926.

28 Akimoto T, Kusano E, Ito C, Yanagiba S, Inoue M, Amemiya M, Ando Y, Asano Y: Involvement of erythropoietin-induced cytosolic free calcium mobilization in activation of mitogen-activated protein kinase and DNA synthesis in vascular smooth muscle cells. J Hypertens 2001;19:193-202.

$\checkmark 29$ Briest W, Homagk L, Baba HA, Deten A, Rassler B, Tannapfel A, Wagner KF, Wenger $\mathrm{RH}$, Zimmer HG: Cardiac remodeling in erythropoietin-transgenic mice. Cell Physiol Biochem 2004;14:277-284.

30 Foster DJ, Moe OW, Hsia CC: Upregulation of erythropoietin receptor during postnatal and postpneumonectomy lung growth. Am J Physiol Lung Cell Mol Physiol 2004;287: L1107-L1115. 